\title{
Challenges of Self-Presentation and Athlete Branding among Saudi Female Exercisers: An Auto-ethnography of a Muslim Saudi Personal Trainer Instagram User
}

\author{
Wesam Basabain ${ }^{1,2}$, Kirsten Macleod ${ }^{2}$, Tony Westbury ${ }^{3}$ \& Afnan Qutub $^{4}$ \\ ${ }^{1}$ Faculty of Communication \& Media, Department of Marketing Communication, King Abdul-Aziz University, \\ Jeddah, Saudi Arabia \\ ${ }^{2}$ School of Arts and Creative Industries, Department of Screen and Media, Edinburgh Napier University, \\ Edinburgh, Scotland \\ ${ }^{3}$ School of Applied Sciences, Department of Sport Psychology, Edinburgh Napier University, Edinburgh, Scotland \\ ${ }^{4}$ Faculty of Communication \& Media, Department of Journalism and Digital Media, King Abdul-Aziz University, \\ Jeddah, Saudi Arabia \\ Correspondence: Wesam Basabain. E-mail: Wbasabain@kau.edu.sa
}

Received: January 25, $2021 \quad$ Accepted: February 2, $2021 \quad$ Online Published: February 28, 2021

doi:10.5539/ass.v17n3p9 URL: https://doi.org/10.5539/ass.v17n3p9

\begin{abstract}
Some athletes have attracted millions of audiences, even if being namely recognised. Cristiano Ronaldo, Neymar JR., and David Beckham have the most Instagram followers on a global scale. Online Social Networks (OSN) allows users to establish their profiles to communicate with others through actions such as follows and comments. Currently, athletes prefer to utilise Instagram for self-branding purposes. Therefore, many studies have examined their practices. From the rising of Model of Athlete Brand Image MABI offline practices to the development of online athlete branding consumers' engagements on social media, many studies have concerned three main categories to build athlete brand image, namely Athletic performance, Attractive appearance, and Marketable lifestyles. As a Saudi female personal trainer who uses Instagram to build a brand image, this auto-ethnography aims to reflect on my personal experiences, including cultural aspects that affect athlete branding strategies. Athlete branding studies have not focused on cultural differences yet. Most Muslim Saudi women are culturally conservative; they cover their bodies in public as a religious practice. This qualitative study describes my own experiences and Instagram visual content selections. It attempts to understand the motives, outcomes, and online self-presentation challenges and strategies of Muslim female exercisers who aim to build their athlete brand image. A key result indicated that the Attractive appearance category was hard to apply to a Muslim female athlete's selfpresentation in her athlete branding strategies. The trainer encountered some cultural challenges, for instance, religious values such as veiling and gender segregation, which conflict with the ability to rely on the selfcharacteristics for branding. Therefore, other strategies were applied, such as presenting body composition before and after test results and testimonials for clients.
\end{abstract}

Keywords: athlete branding, auto-ethnography, model of athlete brand image, online social networks, Saudi female exercises, self-presentation, Instagram

\section{Introduction}

From the perspective of Goffman's self-presentation theory, this study investigates the practices of Athletebranding among Saudi women athletes and exercisers who use online social networks in the field of media and marketing communication. An extensive number of studies on athletes' online self-presentation and self-branding have been conducted in the Western context (Filo, Lock, and Karg 2015). However, there is a lack of studies on Saudi women in this field. While they are ruled strictly regarding their presentation in public, this could affect their online practices.

According to a recent report by CITC (2015), 99\% of Internet users in Saudi Arabia use online social networks, and $43.06 \%$ are Instagram users. Online social networks (OSN) are a significant part of a media revolution that affects youths and adults who are frequent users of these platforms. This new media form has transformed people's ways of living in terms of values, cultures, and attitudes (Safko, 2010). The convergence of digital cameras and Internet-connected devices has simplified access and taking/sharing of visual images, etc. (Lasén \& Gómez-Cruz, 
2009). Inexpensive, sophisticated, and complex digital devices and storages have eased social media use, making them an everyday communication channel (McNely, 2013).

Through visual and textual data, OSN users code their thoughts, feelings, relations, cultures, etc. Accordingly, communication scholars consider these new technologies essential in interpreting humans' conditions in various contexts (Hutchinson, 2016). In addition, an increasing number of OSN users are becoming influencers. These individuals' shared online practices have granted them great numbers of followers; globally, they have turned online platforms into a vast market where they endorse and advertise products, services, and brands (Shan, Chen, $\&$ Lin, 2018). These communication tools have become attractive promotional channels for merchants and service providers.

This study is structured as follows. The theoretical background is presented in Section 2 and the Conceptual Framework in Section 3. Section 4 is a literature review of studies related to the subject. The approach focused on data collection and interpretation is discussed in Section 5. The results are discussed in Section 6. Section 7 is a discussion of the findings.

\subsection{Research Questions}

Based on the above discussion, the following questions have been generated:

RQ 1. How do Saudi female exercisers describe their usage of Instagram?

RQ 2. What motivates Saudi female exercises to post and share their exercise identity?

RQ 3. How do Saudi female exercises experience athlete-branding on Instagram?

RQ 4. What are the challenges encountered by Saudi female exercises in their Instagram's visual selections?

\section{Theoretical Framework}

The study has conducted a critical analysis from two perspectives. Firstly, the self-presentation theory (SPT) proposed by Goffman (1959) was used to study a group of people giving off identity signals for themselves directly or indirectly to please the audience. These individuals aim to control their impressions by adopting a specific strategy to avoid unintended gestures; the given-off signals manipulate understanding among individuals (Jensen Schau \& Gilly, 2003; Lebel \& Danylchuk, 2014a). In other words, people who control their verbal and non-verbal attributes can manage their performance (Goffman 1959; Miller 1995). Consequently, people might be involved in a theatrical performance and act differently in every interaction, which impacts their audiences; for the same reason, SPT has been adapted by numerous studies to evaluate self-branding effects in offline and online contexts. This theory has also been used to find the answer to the main research question that investigate athlete branding strategies that aim to build their brand image and higher their equities.

Secondly, the model of athlete brand image (MABI) generated by Arai et al. $(2014,2013)$ shed light, for the first time, on athletes' brand image and the regulation of their offline self-branding. However, social media special features allow users to present themselves with outsourcing materials such as quotes that they have written or taken from others. Scholars of online social networks have studied online platforms for self-presentation and athlete branding examination purposes (Geurin \& McNary, 2020; Kunkel et al., 2020; Na et al., 2020). The MABI classifies consumers' perceptions of an athletic brand into three main categories:

- Athletic performance, which is related to the frontstage practices that describe the exercise identity of an athlete such as their athletic ability, endurance, strength, and power that distinguish one athlete's performance from another;

- Attractive appearance is illustrated as the chosen clothes, hairstyles, body achievement, and body language, which will communicate the backstage content that differentiates athletes and supports consumers' engagement; and

- Marketable lifestyle, which indicates the backstage characteristics of the athletes' everyday life practices, choices, and hobbies

(Arai et al., 2014, 2013; Doyle et al., 2020; Geurin \& McNary, 2020; Hasaan et al., 2018; Kunkel et al., 2020; Liu \& Suh, 2017; Na et al., 2020)

\section{Literature Review}

\subsection{Instagram in Saudi Arabia}

Saudi Arabia is a peninsula in the heart of the Middle East, with a population of 33.85 million. The country is ruled with conservative Islamic sharia law, and 99 per cent of the population are Muslim (Baker 2016). Saudis use 
Instagram for many purposes, such as cultural sharing, marketing, and learning. In terms of cultural sharing, Qutub (2018) focused on using Instagram and Snapchat to produce selfies and Saudi women's cultural norms, shaping their selfie posting practices. Qutub (2018) analysis of 25 Saudi female who used both platforms found that cultural aspects such as veiling practices and privacy shaped the motives of Saudi women selfie-takers. Women use "virtual walls" to separate male viewers who are not allowed culturally to expose to their posts. While this study reflects posting practices of Instagram and Snapchat selfies to express Saudi women's feelings and opinions, it is limited in its scope, as the study focused on a general sample of Saudi women whereas the current study targets Saudi women interested in sports in particular.

Instagram has also been used for cultural sharing by Saudi individuals and governments officials; the platform has allowed women to share their cultural habits and beliefs with the world and learn about other cultures. By following international celebrities, Saudis can learn about their culture on Instagram (Mouria 2018). Furthermore, culture sharing for Halal items and actions, which are related to Muslims and Islam, spread widely through Instagram posts and captions, being culturally expanded through not only in the Arab Muslim world but also all over the world. In Britain, for instance, Halal food sales reached approximately 2.6 billion GBP in 2011. The Halal lifestyle started as Islamic law and later shifted into a philosophy related to health and ethics of manufacturing a product among the world with different religions. Instagram played a significant role in this spread (Mejova \& Benkhedda, 2017).

Although OSN provide a space for individuals to communicate by posting, sharing, and discussing cultures, they are also a marketing platform for small and large businesses. These platforms offer features that cooperate with businesswomen to promote their products in a conservative culture where women are strictly obliged to take care of their homes and families. Evidence on that purpose is found in Alghamdi (2020), who investigated the role of Instagram to overcome setbacks faced by Saudi businesswomen when managing their business accounts while simultaneously balancing home and work responsibilities. This study findings have contributed to research on the benefits of using Instagram for Saudi businesswomen by conquering a number of challenges, such as advertising products, managing their customer communications, overcoming governmental processes, increasing their income, adapting to cultural and religious challenges, surviving from educational barriers, avoiding difficulties of working in the private sector, and building a strong relationship with their customers. Instagram has a significant impact on women's business development. Saudi students use Instagram for learning purposes. For example, the platform helps fashion design students increase their creativity, knowledge and communicate with other designers in the field (Otayf 2017).

Studies related to Saudi athletes' use of social media focused on building awareness of physical activity among the community to achieve the Saudi 2030 Vision (Baker 2016, Samargandi 2018). However, there is a literature gap on the promotional use and self-branding strategies used by Saudi female exercises. Aa a female Saudi personal trainer who aims to brand my name more strategically via OSN, I highlight the research problem and focus on other female women who work in exercise sports.

\subsection{Saudi Female Exercisers' Lifestyle and Appearance}

Islamic culture considers physical activity a significant part of one's daily routine. Prophet Mohammed said the following in a Hadeeth (messenger's advice): "Teach your children swimming, archery, and horse riding". This Hadeeth shows that Prophet Mohammed encouraged Muslims to enrol in sports and teach such skills to their children (Samargandi 2018).

A group of clerics at the Council of Senior Scholars (CSS) advise the government on religious topics related to human behaviour and traditions through Fatwa (Baxter 2010). In Saudi Arabia, many conservative religious clerics have encouraged women's fitness participation. However, a senior scholar cleric's Fatwa urged the government to uphold a ban on women across all types of sport, warning that it might lead to moral corruption and effects on the female reproductive system (Baxter 2010, Tahran 2013). Thus, Saudi Arabia has effectively prohibited physical education in girls' governmental schools for decades, but this was not applied in private schools. Women have been prevented from participating in sports, and there has been an ongoing debate over whether sports should be permitted (Alenezi 2014).

Although the Saudi Arabian government emphasises women's empowerment in all fields, intending to remove conflicts or gaps between religious and life activities, it has not issued licences for female gyms and fitness centres to avoid this cleric's and the conservative community's criticism. Undercover fitness centres have been attached to hospitals in the form of physiotherapy centres. During this era, Saudi women's gyms were unregulated, creating an environment that could cause harm and reduce creativity and development opportunities among trainers and physical activity practitioners. 
Building an adequate fitness club system is imperative, and the General Presidency of Youth Welfare (GPYW) set up a ministerial committee in 2012 to consider women's sports clubs regulations. This committee was formed to work through the debates and allow sports clubs to open (Saudi Arabia considers allowing 2012). As a result, Saudi female athletes were permitted to participate in the London Olympics for the first time in 2012, although only one Saudi female competitor qualified (London 2012 Olympics 2012).

In 2013, the first Saudi female sports centre opened. The GPYW granted this centre a licence to open legally and contribute to the field of female fitness (Toumi 2013). In 2016, the GPYW became known as the General Sports Authority and signed an agreement with Princess Nora bint Abdulrahman University (PNU) as part of a cooperative process to promote healthy lifestyles. The PNU is a women's campus located in Riyadh, Saudi Arabia's capital. This agreement was a boost to Saudi female fitness that actively serves to increase the number of fitness practitioners from $13 \%$ to $40 \%$ by 2030 and achieve the Saudi 2030 Vision proposed by Crown Prince Mohammed bin Salman (PNU, sports authority 2016).

Despite these challenges, some Saudi women had already been lifting dumbbells, raising bars, kicking sandbags, and running on treadmills. A large portion of this community was educated and recognised the importance of training. Some Saudi women were already athletes, certified personal trainers, Crossfitters, and Les Mills instructors. These athletes have travelled outside of Saudi Arabia or taken online courses to gain qualifications and certifications to work with knowledge and passion.

In 2017, the Ministry of Education implemented a programme to train teachers to start physical education (PE) classes (Saudi ministry set to train, 2017). Saudi Arabia allowed physical education classes in girls' schools after implementing a development programme for 9,000 teachers that started in 2013. Teachers are now responsible for delivering knowledge and building fitness awareness among female students (Saudi public schools, 2017).

\subsection{Athlete Branding}

"Athlete brand" is a term introduced by Arai et al. (2014, p. 98), defined as follows: "a public persona of an individual athlete who has established their symbolic meaning and value using their name, face or other brand elements in the market" (Geurin \& McNary, 2020; Hodge \& Walker, 2015; Kunkel et al., 2020; Park et al., 2020). Construction and promotion of an athlete's brand image are beneficial for various points; it impacts the athlete's price on the market, leading to higher incomes and less marketing communication efforts (Arai et al., 2013; Evans, 2017; Geurin \& McNary, 2020). Decreasing marketing communication operation efforts were described by Duffy and Hund (2015) as they examined the Instagram content of top-ranked fashion bloggers who displayed their attractive appearance and lifestyle activities while travelling with their friends around the world. Another aspect of athlete brand image is attractive appearance and lifestyle activities that athletes need to depict on OSN to brand themselves strategically (Arai, Ko, and Kaplanidou 2013, Montoya and Vandehey 2009).

There are several frontstage and backstage factors that control self-branding on OSN. Scholars have introduced empirical evidence demonstrating how successful athletes' successful self-branding strategies use OSN drawing on the Self-presentation theory and MABI. This use impacts athlete's equity and value, increases their income, positions them as athlete brands, and manages their targeted audience's impression (Arai et al., 2013; GeurinEagleman \& Burch, 2016; Goffman, 1959).

In terms of culture, some studies focused on gender differences of self-presentation on OSN such as appearance, clothing, touches, poses, revealed body parts practices (Gainor, 2017; Geurin-Eagleman \& Burch, 2016; Smith \& Sanderson, 2015; Toffoletti \& Thorpe, 2018). For instance, Smith and Sanderson (2015) examined 27 athletes' Instagram accounts to examine their self-presentation practices on Instagram. The study included content and thematic analysis on these influencers' posted photos and captions. The research found that touching was common among female athletes, as seen in pictures with their arms around friends' waists or shoulders or hugging trophies or animals. Male athletes' posts also had touches such as hands touching a friend's shoulder; Goffman (1959) defines touches as feminine behaviour. The study found significant gender differences in the size of the parts shown in the photos; female athletes had fewer selfies because selfies do not show an influencer's whole figure. Another study found that female Olympic athletes were more likely to share photos of themselves in private settings. In contrast, male athletes posted photos that encouraged their followers to engage in fitness practices (GeurinEagleman \& Burch, 2016).

As a backstage practice, appearance is a key factor in self-presentation theory that may significantly affect the audience's impression management. Appearance is indicated by Arai et al. (2013) as the main variable in the athletic branded-self. Toffoletti and Thorpe (2018) aimed to explore female athletes" appearance and how it shaped their self-presence on Instagram. Appearance determines how women choose to look in their athletic brands and how it impacts their fans' opinions. This practice is called backstage, which allows fitness influencers to the athlete 
brand image. However, because athletes' main purpose is to show their performance to attract employers, fans, and sponsors, Goffman describes it as a front-stage presentation.

Although little research has been conducted to examine athletes' cultural norms that shape their use of social media, their study's findings guided this research. Notably, much of the research has focused on the use of Twitter by athletes (Burch et al., 2014; Hambrick et al., 2010; Lebel \& Danylchuk, 2014a, 2014b, 2012; Marwick \& Boyd, 2011; Pegoraro, 2010; Sanderson, 2013, 2013; Shreffler et al., 2016). On the other hand, Instagram still needs more attention, particularly because it is a visually-focused platform and the most favourable for athletes (Park, Williams, and Son 2020). However, the platform has not been investigated sufficiently in the literature in terms of athletes' cultural norms of self-presentation.

Athletes use OSN for two significant purposes: promoting health and wellness and presenting and building their brand. An extensive body of literature has considered OSN as a physical exercise health promotion tool, investigated its benefits in reducing the risk of heart disease, and identified how it leads to physiological, psychological, and social stability. For instance, social media platforms such as Facebook have been used as an intervention tool for sedentary adolescence to promote healthy behaviours. Moreover, Facebook and Instagram have positively increased health awareness of the Australian 10,000 steps marketing campaign by monitoring impressions, campaign website hits, and app downloads. Furthermore, Instagram and Facebook have allowed users to monitor their fitness and healthy lifestyles by sharing content, including self-tracking technologies reports (such as Fitbit, Polar, and Nike), gym selfies, training techniques, and dieting habits (Al-Eisa et al., 2016; Almerri, 2017; Baker, 2016; Evans et al., 2017; Pilgrim \& Bohnet-Joschko, 2019; Van Itallie et al., 2018; Wojcicki, 2013).

On the other hand, athletes use OSN as a marketing tool for their professional career to promote products, sponsors, charities, and lifestyle activities (Doyle et al., 2020; Geurin \& McNary, 2020; Hambrick et al., 2010; Hodge \& Walker, 2015; Kunkel et al., 2020; Parmentier \& Fischer, 2012; Sharifzadeh et al., 2019). On this topic, Doyle et al. (2020) have studied consumer engagement with athletes' content on Instagram by measuring the number of comments and likes. Scholars have improved the first version of MABI produced by Arai (2014) to include the social media context and consumer engagement. Hambrick and Mahoney (2011) investigated promotion purposes for athletes on Twitter. Geurin and McNary (2020) studied the use of Instagram by Olympic athletes to explore their involvement in ambush marketing. Kunkel, Doyle, and $\mathrm{Na}$ (2020) studied the use of philanthropic efforts to develop athletes' personal brands on Instagram. Another study included Iranian athletes' self-branding strategies on Instagram. Elsmore, a research conducted by Park et al. (2020) explored perceptions of athlete students' selfbranding use in social media.

\section{Research Methods and Tools}

\subsection{Research Design}

A qualitative auto-ethnographical approach is used to describe and analyse personal behaviour concerning culture (Ellis, Adams, \& Bochner, 2011; Hayano, 1979). Digital ethnography is mainly concerned with data types that can be downloaded through the internet only when the participants' connection is mediated and indirect (Pink 2016). Visual ethnography focuses on analysing pictures, videos, and hypermedia (Pink, 2013). A mixed-methods approach was used for this research. A combination of auto, visual and digital ethnography methodologies was adopted to describe and analyse my personal online visual Instagram sharing behaviours through a narrative story to reflect the sub-culture of Saudi female exercisers' shared and different behaviours. The main participant selection procedure in this study is me as an auto-ethnographer for a personal experience.

\subsection{Auto-ethnography and Sport}

Smith and Sparkes (2020) state that qualitative research rarely found in sports journals and books, autoethnographies related to the sports field have also been rarely conducted to build an understanding of psychological, social, and cultural issues related to fitness. The following research has been conducted using this method: athlete auto-ethnographers (Dashper, 2015; Douglas, 2014; Garratt, 2015; McMahon \& McGannon, 2017; Zavattaro, 2014); fans (Knijnik 2015, Parry 2012); fitness developers (Chawansky 2015); referees (Schaeperkoetter 2017); fitness enthusiasts (Baker et al. 2017); sports psychologists (Garratt 2015, Irish, Cavallerio, and McDonald 2018, Buckley 2018); and sport managers (Cooper, Grenier, and Macaulay 2017).

\subsection{Auto-ethnography Ethical Considerations}

As an auto-ethnographer, I have more responsibility than other ethnographers towards my personal story ethics, including to those who are also engaged in my research (Chang, 2016; Lapadat, 2017). My personal story ethics include mentioning how significant it is to not rely on my memory when writing about my Saudi veiled exerciser experience. Although personal memory is useful for auto-ethnographers, it is necessary to consider other sources 
such as Instagram visual content to demonstrate thoughts and practices; this method positions me away from being questioned and criticised for my story (Chang, 2016). Since ethical committees approve and protect the researcher's rights and participants in the research, I anonymise others who appear in my story; I present them using pseudonyms or as anonymous. However, if my relationship with a participant forces their identity apparent, such as a member of my family or a colleague who will be known to other colleagues, I used another technique to ensure privacy by mixing similar characters to avoid points on a specific person (Kantsepolsky, 2019; Bochner \& Ellis, 2016). Furthermore, I asked partners in the story to check my writing to evaluate their effect. I did not find much sensitivity in my story when it is culturally unique, but it may not be shameful or harmful.

\subsection{Trustworthiness of Auto-ethnography}

Auto-ethnography emphasises subjectivity; it was proposed during the 'crisis of representation' in the mid-1980s, pushing back the idea of single reality in social science (Bochner and Ellis 2016). Subjectivity requires the engagement of the readers' emotions and provides a voice to researchers without hiding their influence as significant parts of a research context (Bochner \& Ellis, 2016). Positivists always criticise subjectivity and describe auto-ethnography as talk shows, particularly the evocative aesthetic and emotional auto-ethnography; it is not even structured or framed in its design (Schaeperkoetter 2017). However, this approach has gained popularity in social and cultural studies for decades (Ellis, Adams, and Bochner 2011), particularly for topics related to emotional experiences such as disabilities, illnesses, and divorces, acknowledging research trustworthiness by providing rich information (Dashper 2013, Zavattaro 2014).

\subsection{Veiled Saudi Personal Trainer: My Story}

In 2010, when my second child was born, I received a negative comment on how pregnancy had changed my body. I will never forget this situation; I even remember how I was seated. My appearance means a lot to me, and it was hard to hear negative comments. The next day I put on a three-layer outfit consisting of joggers, a t-shirt, and an Abaya with a scarf, which is the official costume for women in my country. Abayas are the official dress for women in Saudi Arabia, come in different shapes and colours, and tend to disguise the wearer's body shape. By looking into Hijab and Abayas, several modesty practices depend on the individual's cultural background and how religiously conservative her family and she are (Figure 2). I told my driver to turn on the car because this event was before women were granted the right to drive in June 2018 (Hubbard 2017). I left my one-and-a-half month child safely in my mother's hands, who agreed that I should exercise. I started to walk daily on the only walkway in Jeddah, my homeland (Figure 1). An hour daily of the exercise was a struggle, with the lengthy clothing that I used that restricted my gait, as well as suffering very hot and humid weather. However, later, sports Abayas emerged that support comfort and air permeability.

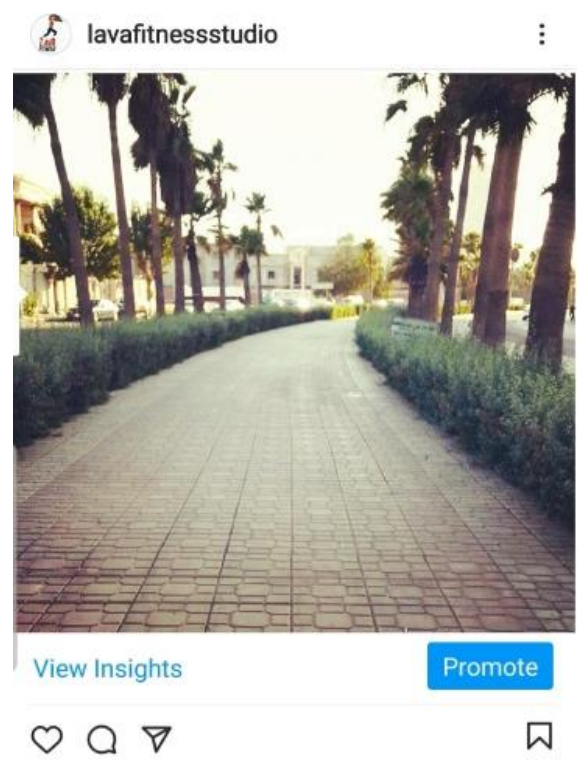

Figure 1. Faisal Bin Fahad Walkway

When women were not culturally allowed to do more than walk outdoors, I changed my walking routine to running with clothing that covered most of my hair and body. To achieve a full gait while running, I folded my Abaya into my knees with full-length sports trousers. Despite my traditional style, I faced the dilemmas of being chased by Haiea. Which is the governmental body that assures moral and religious activities among individuals; they urged 
me to lay down my Abaya, which prevented me from running freely.

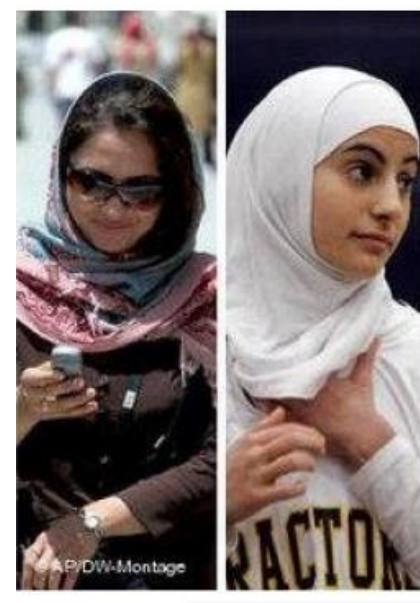

$0 \bigcirc \nabla$
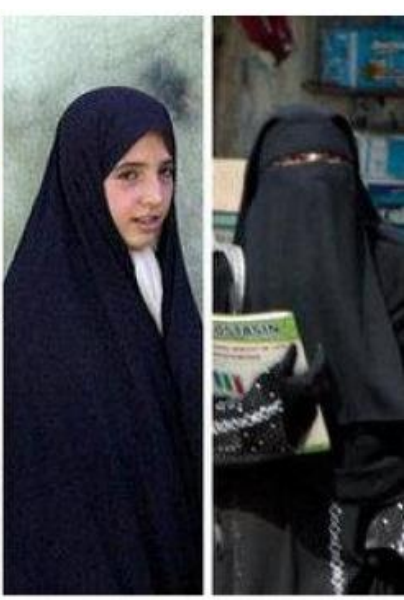

ఐ

Figure 2. Screenshot from "الجدل حول حقوق المر أة في الإسلام,, n.d.

Since 2010, I have taught myself by reading about fitness, weight lifting, and cardiorespiratory wellness improvement. Until 2012, my passion did not waver. The emergence of Instagram helped me to explore more material for education and motivation by following world athletes such as Ulissesworld, Simonpanda, Michelle Lewin, Kayla Itsines, etc., allowing me to gain shallow but useful knowledge. I used to follow any exercise and imitate their techniques. I enjoyed looking at women's fit physiques, which motivated me to not give up on my goals. Instagram tempted me to buy the most fashionable sports clothing brands, supplements, and utilities and manipulated my desire to reach my goals faster by purchasing training and diet plans from industry experts. I admit that Instagram was my entrance to the world of fitness. It meant a lot to me at the first stage when I was a beginner who seeks guidance, and fitness figures on Instagram heavily influenced me.

In 2015, I decided to register for the first time at Gold's Gym; the first centre granted permission to function as a physical therapy centre for women before the gym license was approved by the General Sports Authority. Two years later, the National Academy of Sports Medicine in the US certified me as a personal trainer. I passed the selfstudied exam with a score of 98 of 100 ("Get Certified! Nutrition \& Personal Training Certifications, NASM," n. d.). In 2017, I opened my freelancing private fitness studio, Lava, which works with member testimonials and word of mouth in the form of images of bodily transformations.

I started using Instagram many years ago; I first had a private personal account that I turned into an archive for my personal and family photographs and videos. I used this private account to share my daily photos with my friends and focused on entertainment and receiving likes for my posts. Then, I removed all of my followers because I found that I did not want anyone to track my daily personal life activities, something that should be kept more personal. In this account, which turned into an archive, I use my real full name and my face sketch as a profile photo because it is private, and I used to share it with people that I know.

Following others who inspired my exercise journey, I created a business account to share my inspiration and influence as a personal trainer. This account is public and focused on showing others my fitness identity and seeking clients for training classes and personal training programs, building a cliental base, and building my brand with an awareness of cultural limits. The public account uses my fitness studio name and logo because I wanted to be known as a business owner. I aim to gain people's attention, and I thought this technique would help me spread widely so that more clients will join and sponsors will be attracted.

I am not consistent with posting on my public account, though I do attempt to post as much as possible. I have reached approximately 3,600 followers over four years of using Instagram for this purpose, which has earned mainly by word of mouth. I know that my account is not particularly appealing to the public in general because it is not so attractive in terms of photo quality and selections, advertisement graphics, personal presentation and real before and after photos. Although I allow both genders to access my account because I do not mind setting online training and dieting programs for all, it still does not reach many followers. The page needs a unique strategy to manage and plan the posts to look more attractive, which I am continuously trying to do.

As a trainer, I know that I can share knowledge and present my athletic performance through this application with 
photographs and video. In general, Instagram is a useful marketing tool. As a consumer, I have already bought a lot of items through Instagram. In terms of exercise equipment, I have already bought a lot of training and dieting programs. I remember buying diets and training plans from two American male trainers. I have also bought from a number of fitness clothing brands, knowing them from sponsored posts on Instagram. As a service provider, I also found many calls and registrations through Instagram posts and special occasions. However, I have not achieved what I have wanted to; 3,600 followers are few.

I am interested in demonstrating my workout techniques, gaining clients for the fitness studio, and teaching them healthy eating habits. I usually post for positive effects; for example, sometimes I like to introduce my followers to how to enhance their sedentary lifestyle by exercise such as walking. I use positive testimonials from my clients to let the followers initiate trust in my message as a fitness services provider. I want to express to my followers how successful and consistent I am regarding my biggest dream of being a personal trainer alongside my other personal roles. When I post my workouts, I want them to feel my power, fitness level, and commitment.

Most of my posts express my values but not my personality. My values include respecting the community values, which are among the factors that show in my posts. For example, I cannot show my appearance, which I admit is attractive because I am Muslim. I sincerely believe that it is not necessary to compromise my religious values for any material outcomes. If I post my appearance, I believe that I will perform at a higher standard than I am now in terms of the number of followers, sponsors, and income. However, this technique would conflict with my psychological status, which is spiritually influenced and will grant me more followers who criticise me for not following Muslim values. I am very social and active regarding my personality, and I feel that these characteristics are not shown in my posts. I am healthy and active, which cannot be seen in my posts.

In the beginning, presenting my achievements was not regulated effectively; I only posted general Google quotes and photographs at first (Figure 3). I asked myself, "Wesam, what can you post to gain more followers? How can you be known?" As a follower, I knew deeply that this technique would not work; anyone can surf Google. I felt stuck and did not know what to do to overcome these boundaries and how my posts could be more attractive. I relied on posts from Google and YouTube that communicated my interests and knowledge. Images from Google will never be useful, and people can easily access these images without my help.

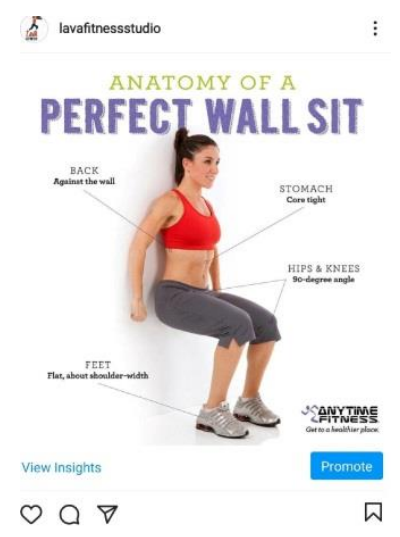

Figure 3. Images were taken from Google

Later, I changed my strategy; I started showing my hands and legs when training depending on my latest fashionable sports shoes to show my appearance (Figure 4). I added some before and after body composition tests and testimonials of my clients to the feed to demonstrate my training results (Figure 5). Moreover, I posted videos of my trainees' legs while doing the exercises but was unable to increase the number of followers that I have. Therefore, I began to post exercises with mostly modest clothing, not focusing on my face to prevent bothering conservative followers and family members (Figure 6). I have posted some recipes to grab the attention of healthy eaters (Figure 7). I included some photos indicating the education courses I attended to prove my knowledge (Figure 8). Some athletic performance proof was posted to show my power but without being attractive or showing my real lifestyle (Figure 9). Moreover, I have posted some photographs of my disguised trainees in class (Figure 10). Following these steps, I have begun to attract more attention and to gain more followers; their comments and likes encourage me to continue because I feel that the public appreciates my posts. 


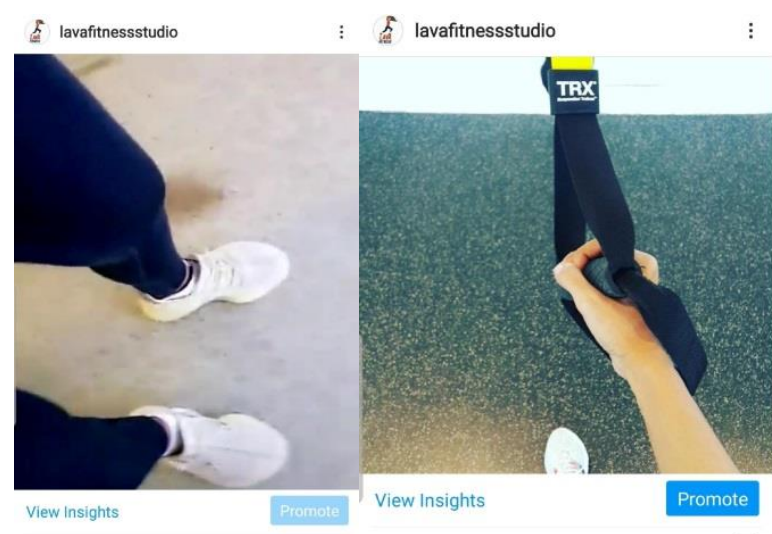
$\circ \bigcirc \nabla$
๑ $\bigcirc \nabla$
ఐ

Figure 4. Beginning to show a body part
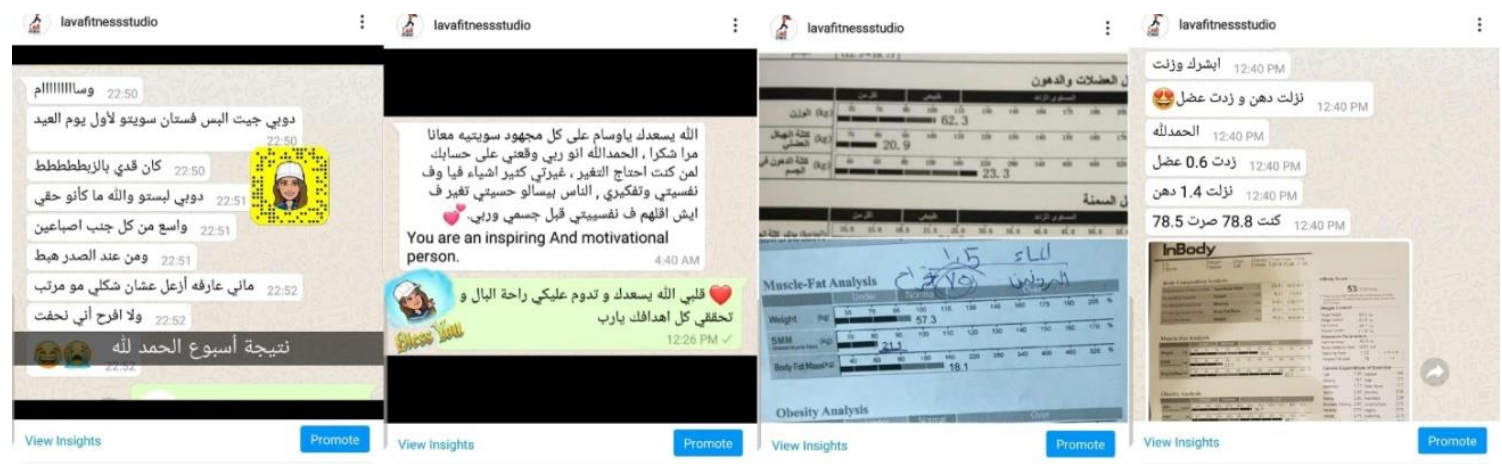

$\circ \circ \nabla$

๑ $\bigcirc \bigcirc \nabla$

๑ $\bigcirc \vee \nabla$

๑ $\bigcirc \nabla$

๑

Figure 5. Clients' results and testimonials

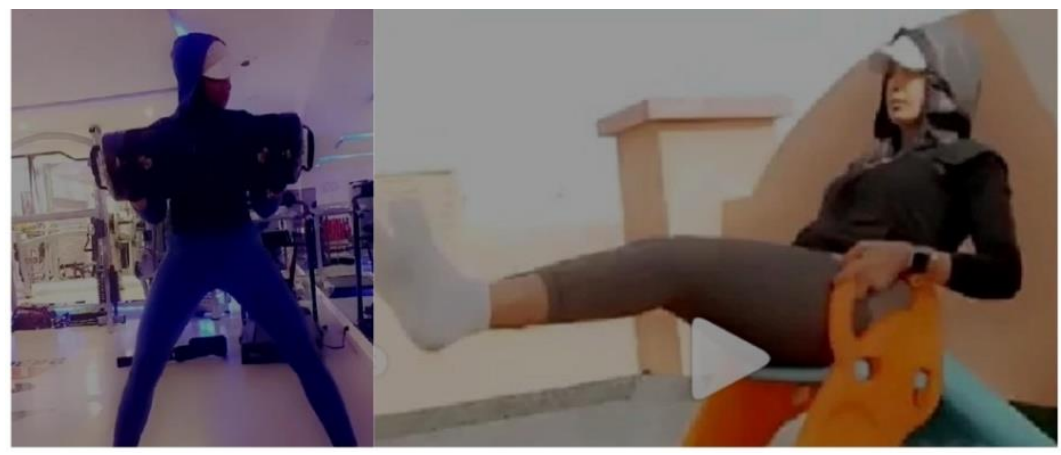

Figure 6. My presence as a Saudi trainer on Instagram

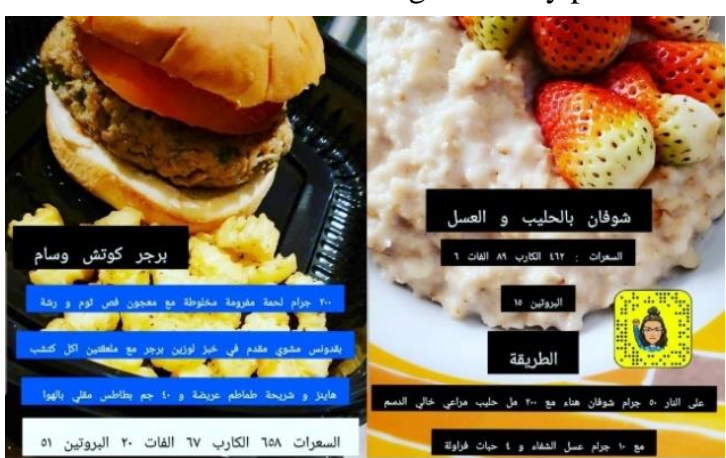

Figure 7. Healthy calorie-counted recipes

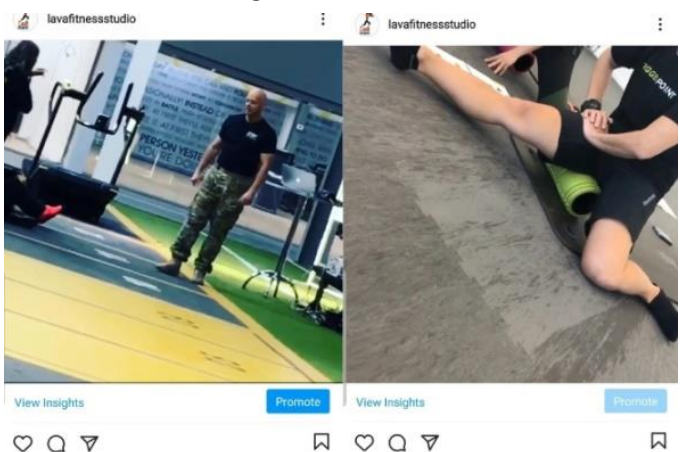

Figure 8. Fitness educational courses that I attended 


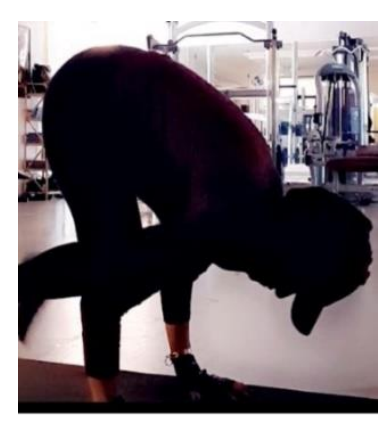

Figure 9. Example of my athletic performance

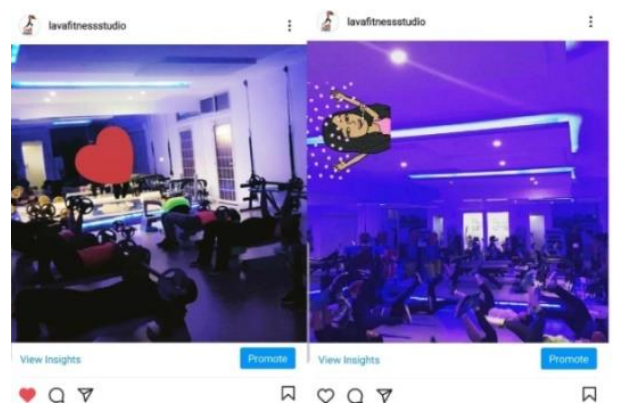

Figure 10. In-class photos

Although being a mother and a worker holds me back from concentrating on my social media influence, I post my workouts shared with my children to let my followers think that nothing can stop them from being active (Figure 11). I also invite women to try riding a bicycle outdoors (Figure 11). Before 2018, riding a bicycle was prohibited. Sometimes cultural reasons hold me back from evolving, such as having conservative relatives who feel that it is harmful or disrespectful to see me on public social media. Having these people around holds me back. However, I believe that it is difficult for me to create a brand of myself without a powerful media presentation.

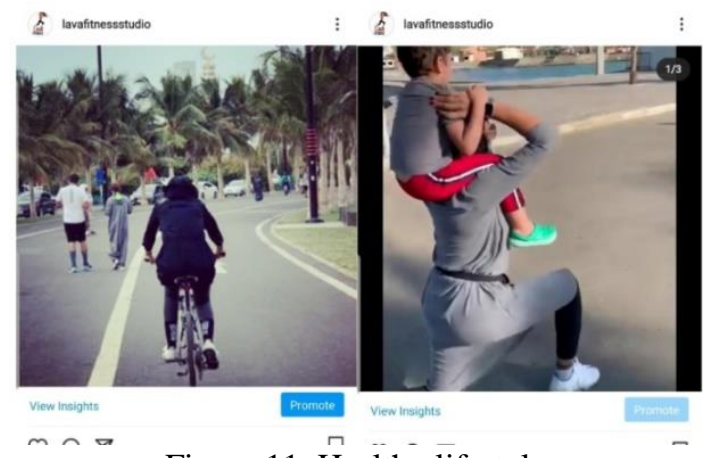

Figure 11. Healthy lifestyle

Branding yourself means being known by others who associate your name with positive or negative feelings. Therefore, I have chosen to post my workouts with moderate clothes, healthy meals, testimonials, and transformation that can be seen through the change in my kegs. I cannot post more because my family is conservative and could be harmed if I tried to include broader strategies. In real, I always think that I deserve a perfect position when it comes to my athletic performance, appearance, and healthy lifestyle. Many girls who show more of themselves are more famous than I am. I sometimes become frustrated but do not wish to compromise values.

Because I learned to be active from others who post on Instagram, I aim to teach others. Because I buy from Instagram, I hope that others find my account and come to my fitness studio to attend classes. Instagram still makes an ideal archive for my journey and helps my clients gain feedback to attract others. The use of the platform also encourages me to stay in the field when I feel down and depressed; it has helped me build a network with other trainers in the field and gave me confidence that I will always be a trainer if I am consistent. Fear of the community, my family, and men who are not used to seeing Saudi women in moderate fitness clothes is a significant challenge.

Being asked for media interviews is terrifying, and I could not accept three TV popular shows interviews that invited me to talk about my Saudi female personal trainer's achievements when my family forbade it. More challenges that I have faced that I do not have the skills to produce quality images, not having a coherent theme for my account, and not knowing how to use all Instagram features. Male beginner photographers found me on Instagram and offered to collaborate with me to enhance my photographs and tag them in return. Unfortunately, I refused their offers because of gender segregation issues. Although working with members of the opposite gender is culturally accepted by some Saudi people, the men in my family do not accept it. Eventually, I decided not to hire female photographers because of the expense.

I am convinced that being Muslim prevents me from showing my body or my clients' transformation journeys, which is important in athlete branding. Others can utilise this tool to present their services on Instagram. However, I cannot compromise my values and try to show things that are suitable for my religion, as well as for my culture and my family. Most of my family do not know about my public account; others may know but never comment about it. Some of my family members keep reminding me not to show more and keep being a good Muslim. 
Moreover, some of my relatives think that being famous or known will morally corrupt me and lead me to ignore my values.

In terms of appearance, I wear Abaya or moderate clothes that barely show my attractiveness, a cap, and a hoody, and I cover some areas by using stickers to hide them from the scene. I chose this appearance as practising Muslim attitudes and preventing criticism from others. Though I do not want to compromise my values, I would like to be famous. My body is something that shows how professional I am, but I hide it, which lessens the appeal of my account and has a negative impression on my non-Muslim followers. I remember one trainer making me cry just for being veiled, and he did not treat me in the same way as others in the class; he thought that I was not qualified or knowledgeable enough to attend his course. Despite this negative trainer's opinion, I was able to pass the course. Hiding my body means that my account is not attractive regardless of what I do; being veiled restricts me from being my real self.

I perform well in exercising and leading my clients to success through their transformation journeys. Sometimes, I feel that if the women were mixed with men, there would be energy. Female gyms are boring because all clients have the same goals. Sometimes, I dream of having my husband training with me in the gym. I do not mind being veiled with my husband, but I would like to get support from other male trainers. Women have the power but watching how males workout enhances my performance somehow. When I have trained with my husband in some USA gyms, I felt progression, support, and encouragement.

If I show my lifestyle or attractive appearance, I know that I will receive sexual comments from men. I do not enjoy receiving these comments. Other women may want to receive all attention, both negative and positive, to become famous quickly and have higher engagement, which makes brands sponsor them. More clients will want to be instructed and trained by these women. Enhancing my photo and video quality, sharing more educational posts, recipes of healthy food, including more clients' testimonials, and using an attractive theme and colours, may improve my branding position to satisfaction without compromising my values.

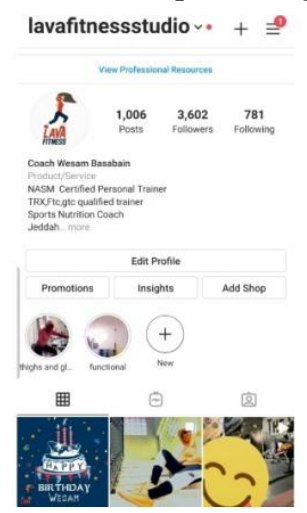

Figure 12. Followers number after three years of using Instagram

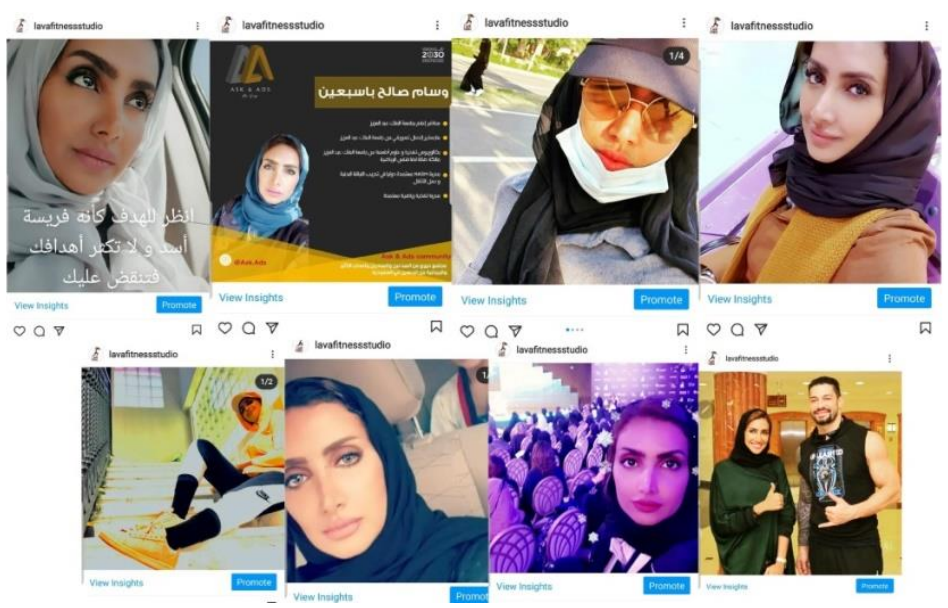

Figure 13. Face and body reveal

In the almost four years of using these self-presentation methods, the Lavafitnessstudio Instagram account has reached 3,602 real followers (Figure 12). I have gradually shifted my self-presentation journey by showing more of myself to brand myself (Figure 13). I also upload classes' advertisement posts among these images (Figure 14). 


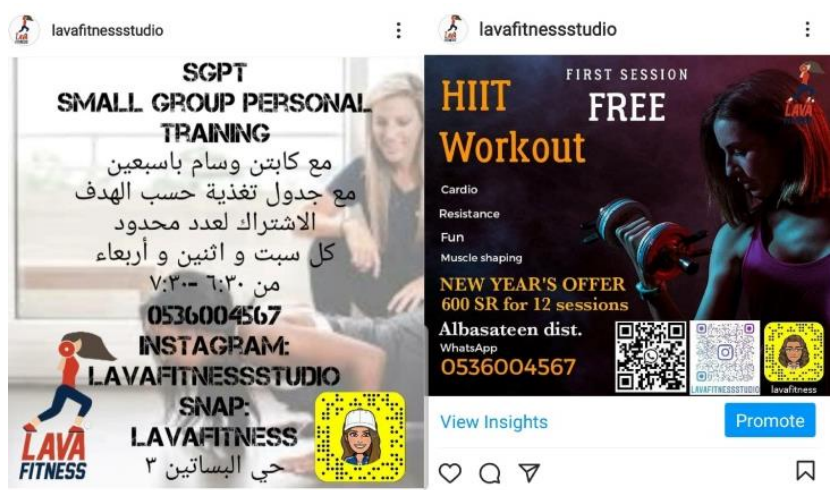

Figure 14. Fitness classes advertisements and offers

\section{Results}

This study adopts Davis et al.'s (2012, pp. 361-362) thematic analysis guidelines as follows: (1) analytical reading and notation for the story; (3) generating codes, (4) specifying thematic categories, (5) formulation and building connections that build understanding and answer research questions. This procedure is called thematic analysis (TA). It is defined as follows: "form of analysis which has the Theme as its unit of analysis, and which looks across data from many different sources to identify themes" (Braun \& Clarke, 2013, p. 455). Davis et al. (2012) also define this approach as follows: "A method of categorising data into thematic categories" (p. 343).

RQ 1 examined how Saudi female exercises describe their use of Instagram. Following analysis, six themes were generated. The themes emerged throughout the story in different areas. The first theme was "Archiving" and could be seen using Instagram as a storage platform. The second theme raised through the analysis was "Branding" and how one aims to reach more followers and become famous. The third theme was "Entertainment",, which involved using Instagram to post and connect with others in the field. The fourth theme was "Motivation" and involved her many aspects of being motivated by other athletes and sharing motivation with followers. The fifth theme was "Inspiration", and involved how before and after images can affect motivation. The final theme raised through the story regarding Instagram usage was "Shopping"; I have bought many sports facilities and clothing by athletes sponsored by brands. Clients have purchased many registrations for personal and group training classes advertised on my account.

\section{Archiving}

I use two different accounts, the first of which is a personal account that has turned into an archive:

I first had a private personal account that I turned into an archive of my personal and family photos and videos.

The second account is public for my business as a trainer and is described as follows:

Instagram still makes a perfect archive for my journey and feedback from my clients to attract others.

\section{Branding}

One of my key motivations for having an Instagram account is to create my brand as an athlete:

I use an attractive theme and colours, which may improve my branding position to satisfaction without compromising my values.

I also state that self-branding is important in the following way:

I have gradually shifted my self-presentation journey by showing more of myself to brand myself.

\section{Entertainment}

I express enjoyment for using Instagram and connecting with and being inspired by others:

I enjoyed looking at women's fit physiques.

I also discuss my account as a source of entertainment:

I used this private account to share my daily photos with my friends and focused on entertainment and receiving likes for my posts.

\section{Motivation}

On my business account, I share motivational posts and feels motivated by posts by other trainers. Motivation by other world-famous trainers can be seen in the following quotes: 
The emergence of Instagram helped me to explore more material for education and motivation by following world athletes such as Ulissesworld, Simonpanda, Michelle Lewin, Kayla Itsines, etc., allowing me to gain shallow but useful knowledge.

I enjoyed looking at women's fit physiques, which motivated me to not give up on my goals.

Sharing motivation to her followers was found in

Although being a mother and a worker holds me back from concentrating on my social media influence, I post my workouts shared with my children to let my followers think that nothing can stop them from being active.

\section{Inspiration}

As an influencer, I also inspire others to exercise:

Following others who inspired my exercise journey, I created a business account to share my inspiration and influence as a personal trainer.

In addition, I have been inspired by following other athletes on Instagram:

I follow others who inspired my exercise journey.

\section{Shopping}

Instagram has proven that it is an efficient online marketing platform:

Instagram is an effective marketing tool.

I have also bought a number of items from Instagram:

Instagram tempted me to buy the most fashionable sports clothing brands, supplements, and utilities.

Moreover, she bought and sold several services like

In terms of exercise equipment, I have already bought a lot of training and dieting programs. I remember buying diets and training plans from two American male trainers. I have also bought from a number of fitness clothing brands, knowing them from sponsored posts on Instagram. As a service provider, I also found many calls and registrations through Instagram posts and special occasions.

I also aim to sell more through Instagram:

Because I buy from Instagram, I hope that others find my account and come to my fitness studio to attend classes.

RQ 2 investigated what motivates Saudi female exercisers to post and share their exercise identity. Motives lead to behaviours, and athletes who depict their exercise identity have motives behind their presentation practices. My story of Instagram exercise identity sharing motives has generated three themes as follows: "Fitness consistency", "Showing power", and "Client and sponsor attraction". I believe that posting my workouts makes me motivated to be consistent, gives me the ability to show how powerful she is, and attracts more clients to purchase fitness classes, which leads to sponsors finding her.

\section{Fitness consistency}

I post about fitness to stay consistent with workouts and teach others also to stay consistent with their fitness goals, stating the following:

I want to express to my followers how successful and consistent I am regarding my biggest dream of being a personal trainer alongside my other personal roles.

\section{Showing power}

One of my motives for presenting my fitness identity is the desire to show my fitness level and the focus on my goals:

When I post my workouts, I want them to feel my power, fitness level, and commitment.

I post proof of my athletic performance to show my power.

\section{Client and sponsor attraction}

I discuss the motives of recruiting clients and sponsors when sharing my exercise identity:

This account is public and focused on showing others my fitness identity and seeking clients for training classes and personal training programs.

Furthermore, 
I hope to grasp people's attention and many followers to attract more clients.

I am interested in showing my workout techniques and gaining clients for the fitness studio.

I want to attract sponsors to work with me.

If I post my appearance, I believe that I will perform at a higher standard than I am now in terms of the number of followers, sponsors, and income.

RQ 3 explored how Saudi female exercisers experience athlete branding on Instagram. I use a number of techniques to create a personal brand. The thematic analysis generated five main themes, namely "Athletic performance", "Appearance", "Healthy lifestyle", "Clients results and testimonials", and "Proof of education and knowledge".

\section{Athletic performance}

One of the methods used on my account is performing exercises to the followers to show them the correct techniques, as well as my fitness level and power:

I am interested in showing my workout techniques.

When I post my workouts, I want my followers to feel my power, fitness level, and commitment.

I post proof of my academic performance to show my power.

\section{Moderate appearance}

I have passed through three stages of showing myself on Instagram:

I started showing my hands and legs.

I post my workouts with moderate clothes not focused on my face.

I have gradually shifted my self-presentation journey by showing more of myself to brand myself.

\section{Healthy lifestyle}

I also aim to share my healthy lifestyle with my followers:

I post my workouts shared with my children.

I teach them healthy eating habits.

I have posted some food recipes to grab the attention of healthy eaters.

\section{Education and knowledge}

Some of the Instagram posts shared were focused on presenting how the influencer is educating herself in fitness to convince her followers to build trust:

I included some photos indicating the education courses that I have attended to prove my knowledge.

\section{Clients' results and testimonials}

I state the following:

I added some before and after body composition tests and testimonials of my clients to the feed to demonstrate my training results.

In 2017, I opened my freelancing private fitness studio, Lava, which works with member testimonials and word of mouth in the form of images of bodily transformations.

RQ 4 examined the challenges encountered by Saudi female exercisers in Instagram visual content selections. I have encountered a number of challenges in my selections on Instagram. Therefore, themes were categorised into three main categories, with several sub-codes for each category. The first theme is "Cultural challenges", and challenges are associated with two sub-codes, namely "religious values (Veiling, Gender segregation)" and "family traditions", as well as "Followers' bullying". The other category is the "Personal challenges", and sub-codes are as follows: "Low Skills", "Low commitment", "Low comfort" and "fake life". The third category was related to the rules of the country by the Saudi government, such as "Governmental rules", and the sub-codes "Lack of sports' facilities" and "Women's rights."

\section{Cultural challenges}

I am Muslim; she never minds to veil her attractiveness since she stated:

If I post my appearance, I believe that I will perform at a higher standard than I am now in terms of the number of 
followers, sponsors, and income, but I cannot compromise my spiritual values.

I feel stable when I follow the Islamic rules, but they challenge my branding strategy and self-presentation selections. Veiling is my own choice:

\section{I changed my walking routine to running with clothing that covered most of my hair and body.}

However,

To achieve a full gait while running, I folded my Abaya into my knees with full-length sports trousers.

An hour daily of the exercise was a struggle at that time; with the clothing that I used, I suffered very hot and humid weather.

I have also faced racism when attending a fitness course given by a male trainer just because I was veiled:

I remember one trainer making me cry just for being veiled, and he did not treat me in the same way as others in the class; he thought that I was not qualified or knowledgeable enough to attend his course. Despite this negative trainer's opinion, I was able to pass the course.

The second religious aspect that was identified in my story was "Gender segregation". I believe that isolating men from women have advantages and disadvantages and deal with men at work:

I allow everyone to follow me, and I do not mind setting online training and dieting programs for both genders.

Although I believe that wearing modest clothing allows me to have closer relationships with men, I do not work with men. One male member of my family prohibited working with men:

I refused their offers because of gender segregation issues.

Although it was culturally accepted for some Saudi people, the men in my family did not accept it.

Conflict occurs when religions intersect with traditions. I would enjoy training with men, and I believe that having a male preserve at my centre would motivate other women because men are more powerful. On the other hand, I believe that mixing genders will lead to harassment:

If I show my lifestyle or attractive appearance, I know that I will receive sexual comments from men. I hate receiving these comments.

Religious values and family traditions overlap. Some families are strict and react negatively when it comes to their privacy and women's reputations. "Family traditions" refer to what one's family deems as acceptable and are of particular importance to me:

Several modesty practices depend on the individual's cultural background and how religiously conservative her family and she are.

Therefore, I began to post exercises with mostly modest clothing, not focusing on my face to prevent bothering conservative followers and family members.

I cannot do more because my family is conservative.

Fear of the community, my family, and men who are not used to seeing Saudi women in moderate fitness clothes is a significant challenge.

I could not accept three TV popular shows interviews that invited me to talk about my Saudi female personal trainer's achievements when my family forbade it.

I cannot compromise my values and try to show things that are suitable for my religion, as well as for my culture and my family.

All of these responses suggest strong and respectful family relations.

Another theme that arises is the cultural challenge of "followers' bullying":

I aim to respect my community.

I am afraid of the community.

I have received criticism for not clearly showing my Muslim faith.

I am to prevent harassment from more conservative followers.

I sometimes act to prevent criticism.

Personal challenges 
I mentioned many challenges, including my skill level, lack of commitment, discomfort, and not showing my real personality. Specifically, I discuss my lacking photography skills and no free time:

My account is not attractive in terms of photo quality, selection, and advertising.

I face challenges in terms of my low-quality image skills, not having time to focus on having a coherent theme, and not knowing how to use all of the features of Instagram.

I mention my inconsistent posting:

I am not consistent with posting on my pubic account.

I also discuss hiding my real life:

I shy away from showing my attractiveness or photos of myself.

I feel that being veiled prevent me from being myself

Low levels of comfort were also expressed:

I am not able to run freely.

I am uncomfortable when I have to run in multiple layers of clothing in the heat.

\section{Governmental Rules}

Some rules in Saudi Arabia restricted the trainer from building her brand name, illustrated in sub-codes such as "lack of sports facilities" and "women rights". Until recently, women were prohibited from participating in sport:

Before 2018, riding a bike was prohibited.

I started to walk daily on the only walkway in my hometown of Jeddah.

Women in Saudi Arabia encountered conservative rules that diminished after 2018 when Crown prince Muhammed bin Salman focused on balancing religiosity with modernism:

Despite traditions, I faced the dilemmas of being chased by Haiea. This governmental body assures moral and religious activities among individuals; they urged me to lay down my Abaya.

The governmental restrictions imposed on the trainer slowed her branding progress. Recently, the government has supported women to allow them to achieve the goals of the 2030 Vision.

\section{Discussion and Recommendation}

Athletes have the opportunity to capture the attention of consumers with their physical skills and energetic personalities, and they make attractive representatives to market products (Hambrick and Mahoney 2011). This auto-ethnography used a personal experience of a Saudi female personal trainer and her Instagram usage. It focused on how she used Instagram generally and what strategies she implemented to brand her name within the restrictions of cultural norms (veiling, gender segregation) as being a Muslim woman. Online social networks OSN like Instagram have proved to be a powerful way of reaching millions of consumers (Berg and Sterner 2015) and being the most favourable platform for athlete branding (Park, Williams, and Son 2020). Athletes can communicate directly with their followers and build their athletic persona in the way they prefer, with less interference from a third party. Although OSN have the features and offers the opportunity to attract millions of consumers, the user's selections of what to share are the main concern to success in targeting more audiences.

\subsection{Theoretical Implications}

Following Goffman's $(1959 ; 1979)$ sociological perspective of self-presentation theory SPT and Arai et al. (2014, 2013) Model of Athlete Brand Image MABI. This study analyses Saudi Muslim female personal trainer who use public social media platforms -Instagram- as a promotional tool with numerous cultural restrictions to brand an athlete image. Past research has determined gender differences in Instagram self-presentation strategies for athletes (Gainor, 2017; Geurin-Eagleman and Burch, 2016; Smith and Sanderson, 2015). Researchers have investigated how athletes have applied the three categories of MABI to their offline and online presentation (Park, Williams, and Son 2020, Hodge and Walker 2015). However, studies on specific cultural differences, such as being a veiled Muslim athlete that affect athlete branding strategies, have not been found in the literature. This study's findings provide the strategies of athlete branding of Saudi personal trainer who used Instagram to market for herself as a professional and for her fitness studio's activities to attract more consumers. This study will benefit other Muslim women worldwide who use social media to build their brand name.

This study builds a comprehensive theoretical framework that has been used for almost a decade studying athlete presentation and branding to determine whether it could apply the MABI by Arai et al. $(2013 ; 2014)$ to Muslim 
female athletes. I found that several factors hinder this strategy, which is largely based on my experience as a Muslim woman and a personal trainer.

Previous studies have identified specific cultural factor of gender differences. For instance, Smith and Sanderson (2015) compared twenty-five Instagram accounts of males to females' social media usage in the lens of Goffman's gender analysis perceptions such as ritualistic touching, size of the athletes in the photographs, and the focal point of the presentation. For example, males found more interested in headshot and chest focus photos, but females focused on far distance photography.

Gainor (2017) have evaluated twelve Instagram accounts contents for six females and six males athletes, following Goffman's four gender analysis categories; feminine touch, ritualistic touch, licensed withdrawal and ritualisation of subordination. This study found that, unlike males, females are more in tune with the gender expectations on Instagram when they are not considered sportspeople; thus, they show more feminine look than show their athletic performance. Although the previous studies found significant differences in terms of gender, they did not serve the main purpose of the current research, which is the Muslim cultural norms of females.

Regarding the promotional purposes of self-presentation, Hodge and Walker (2015) have investigated the concept of athlete branding challenges through professional athletes' perceptions. Through interviews with fifteen professional golfers, the study found three major challenges that restrict those athletes from building their branded persona; lack of knowledge, lack of time and/or support, and differences in career stage. These key findings are in alignment with the main key result of the current study. In this study, I found that personal challenges, such as low skills and low commitment, are challenging in terms of building my athletic brand name.

Park, Williams, and Son (2020) conducted qualitative phenomenological interviews for eleven student-athletes who use Instagram for athlete branding. Key themes were found by analysing the interviews data, including benefits and barriers of social media use, social media strategies, and concerns about negative consequences of social media. The first theme supports the findings of the current study, which implies that Instagram as a tool is beneficial for branding an athlete for the features it offers to the users. Another key result that rises from Park and colleagues study supports these study findings. When looking into the challenges of athlete branding through Instagram, they called it a lack of awareness of personal branding via social media aligns with lack of knowledge in the current study. Until now, I only found supportive finding to the personal challenges of athlete branding. Therefore this study concludes a major aspect that discovers the Muslim cultural challenges: veiling and gender segregation in terms of athlete branding contexts. Moreover, the governmental rules such as lack of sports facilities and women rights challenge an athlete to brand their names.

\subsection{Practical Implications}

Key findings were raised through the thematic analysis that built an understanding of how cultural and personal challenges and governmental rules affected athlete branding strategies choices; for instance, religious values such as veiling and gender segregation conflict with attractive appearance and athletic performance presentation selections. Previous studies found several strategies implemented by athletes when using social media for building a brand name; for instance, Park, Williams, and Son (2020) found that student-athletes tend to present their athletic identities and performance. This supported my study findings when one of the thematic analysis results indicated that the Muslim personal trainer utilises athletic performance as a strategical way to brand her name.

The study also found significant strategies adopted by the trainer to overcome the previous challenges. These strategies contribute to athlete branding for Muslim female trainers, such as clients' results and testimonials and Education and knowledge quotes which she believes it has mostly attracted other clients to follow and call for registrations. This study list a number of motives and outcomes of using Instagram by a personal trainer. As a recommendation for the next research, athlete branding researchers in the Muslim world may investigate more strategies to enhance the process and evaluate the content of Muslim trainers struggling to build their brand image, study other Muslim contexts and other platforms.

\section{Conceptual Model}

The conceptual model proposes that the marketable lifestyles and attractive appearance categories of MABI are related to backstage practices. When posting a Muslim woman's visual content, they become affected by cultural norms such as veiling and gender segregation. The researcher included two significant strategies to overcome the challenges; clients' results and testimonials and Education and knowledge quotes. The suggested solutions for Muslim female athletes to enhance their athlete branding strategy are presented in (Figure 15). 


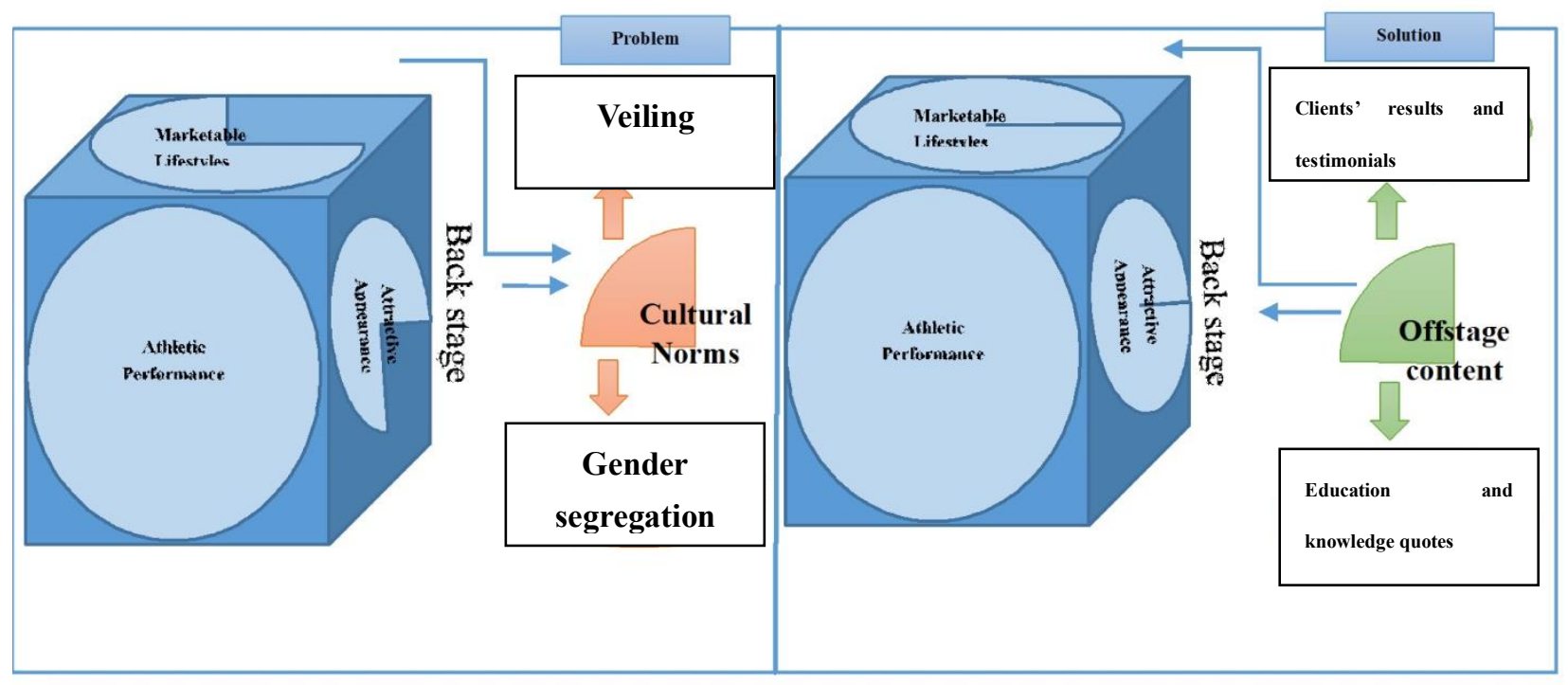

Figure 15. Conceptual model of "Muslim Women Athlete Brand Image" (MWABI)

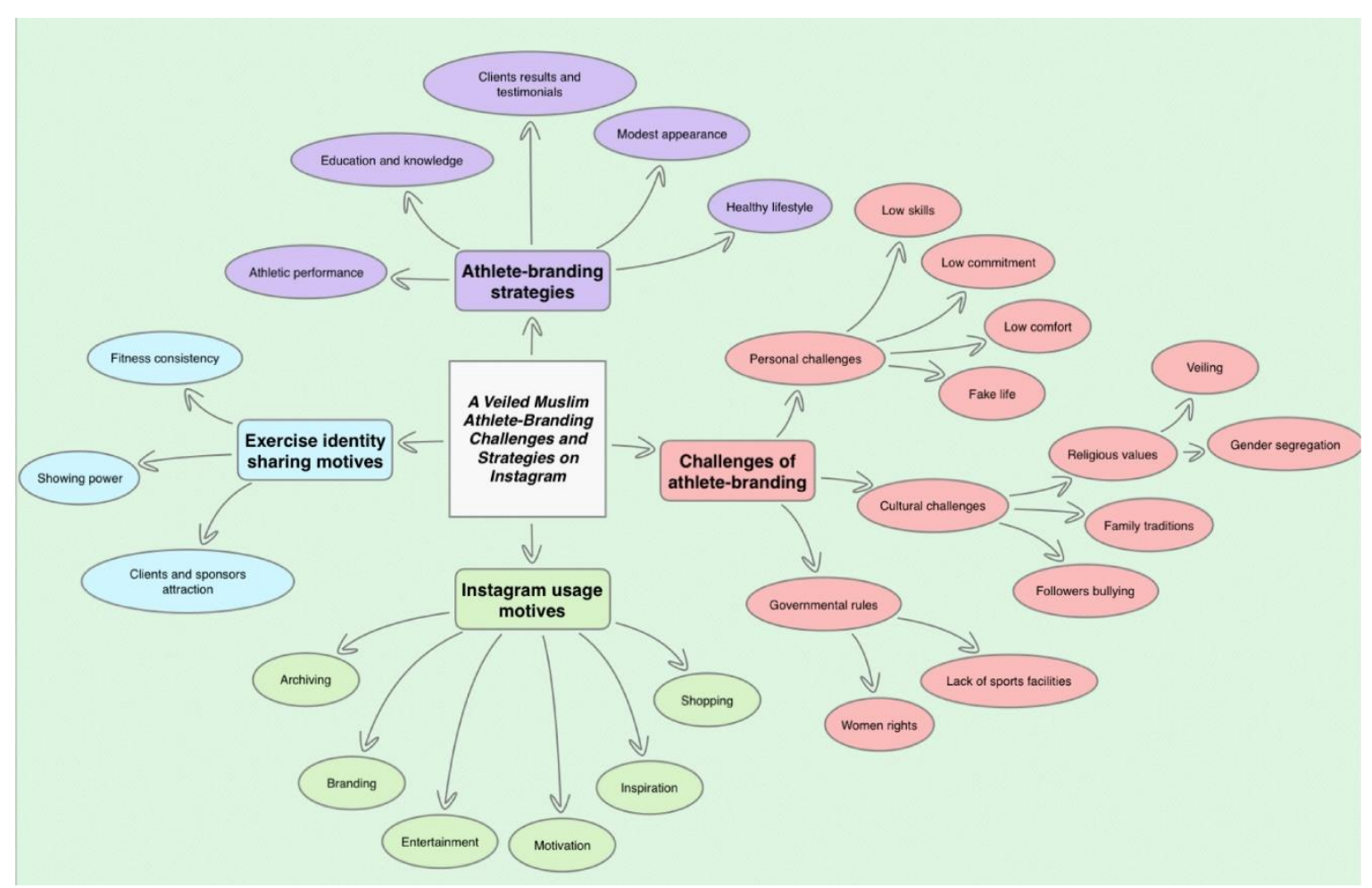

Figure 16. Visualisation of the Story Findings

\section{Acknowledgements}

The author thanks all of the authors in any sources referenced. Their work contributed to the achievement of the objectives of this research.

\section{References}

Al-Eisa, E., Al-Rushud, A., Alghadir, A., Anwer, S., Al-Harbi, B., Al-Sughaier, N., Al-Yoseef, N., Al-Otaibi, R., and Al-Muhaysin, H.A. (2016) 'Effect of Motivation by "Instagram" on Adherence to Physical Activity among Female College Students'. BioMed Research International 2016 
Alenezi, L. جامعة طيبة [online] مدارسة المراة للرياضة في الفقه الإسلامي (2014) available from <http://0o106yui1.y.http.search.mandumah.com.kau.proxy.deepknowledge.io/Record/620902> [17 October 2020]

Alghamdi, H.M. (2020) 'The Impact of Instagram Uses by Saudi Businesswomen on Promoting the Creation and Management of Their Businesses'. Multi-Knowledge Electronic Comprehensive Journal For Education And Science Publications (MECSJ) (29)

Almerri, R.S. (2017) Exploring the Role of Celebrities' Instagram Accounts in Changing the Behaviour of Consumers: Case Study of Kuwait. Brunel University London

Arai, A., Ko, Y.J., and Kaplanidou, K. (2013) 'Athlete Brand Image: Scale Development and Model Test'. European Sport Management Quarterly 13 (4), 383-403

Arai, A., Ko, Y.J., and Ross, S. (2014) 'Branding Athletes: Exploration and Conceptualization of Athlete Brand Image'. Sport Management Review 17 (2), 97-106

Baker, B.J., Zhou, X., Pizzo, A.D., Du, J., and Funk, D.C. (2017) 'Collaborative Self-Study: Lessons from a Study of Wearable Fitness Technology and Physical Activity'. Sport Management Review [online] 20 (1), 114-127. available from <https://linkinghub.elsevier.com/retrieve/pii/S1441352316300663> [14 November 2020]

Baker, R. (2016) Online Social Networks and Saudi Youth Participation in Physical Activity. Brunel University London

Baxter, E. (2010) 'Saudi Cleric Says Sport Corrupting Women'. Arabianbusiness.Com [online] available from <https://search.proquest.com/docview/325318443?accountid=43793>

Berg, L. and Sterner, L. (2015) Marketing on Instagram: A Qualitative Study on How Companies Make Use of Instagram as a Marketing Tool.

Bochner, A. and Ellis, C. (2016) Evocative Autoethnography: Writing Lives and Telling Stories. Routledge

Braun, V. and Clarke, V. (2013) Successful Qualitative Research: A Practical Guide for Beginners. sage

Buckley, R.C. (2018) 'Aging Adventure Athletes Assess Achievements and Alter Aspirations to Maintain SelfEsteem'. Frontiers in Psychology 9, 225

Burch, L.M., Clavio, G., Eagleman, A.N., Major, L.H., Pedersen, P., Frederick, E.L., and Blaszka, M. (2014) 'Battle of the Sexes: Gender Analysis of Professional Athlete Tweets'. Global Sport Business Journal 2 (2), $43-62$

Chang, H. (2016) Autoethnography as Method. vol. 1. Routledge

Chawansky, M. (2015) 'You're Juicy: Autoethnography as Evidence in Sport for Development and Peace (SDP) Research'. Qualitative Research in Sport, Exercise and Health [online] 7 (1), 1-12. available from <http://www.tandfonline.com/doi/abs/10.1080/2159676X.2014.893900> [14 November 2020]

Cooper, J.N., Grenier, R.S., and Macaulay, C. (2017) 'Autoethnography as a Critical Approach in Sport Management: Current Applications and Directions for Future Research'. Sport Management Review [online] 20 (1), 43-54. available from <https://linkinghub.elsevier.com/retrieve/pii/S144135231630033X> [14 November 2020]

Dashper, K. (2015) 'Revise, Resubmit and Reveal? An Autoethnographer's Story of Facing the Challenges of Revealing the Self through Publication'. Current Sociology [online] 63 (4), 511-527. available from <http://journals.sagepub.com/doi/10.1177/0011392115583879> [14 November 2020]

Dashper, K. (2013) 'Getting Better: An Autoethnographic Tale of Recovery from Sporting Injury'. Sociology of Sport Journal 30 (3), 323-339

Davis, C., Powell, H., and Lachlan, K. (2012) Straight Talk about Communication Research Methods . Dubuque, IA: Kendall.

Douglas, K. (2014) 'Challenging Interpretive Privilege in Elite and Professional Sport: One [Athlete's] Story, Revised, Reshaped and Reclaimed'. Qualitative Research in Sport, Exercise and Health [online] 6 (2), 220 243. available from <http://www.tandfonline.com/doi/abs/10.1080/2159676X.2013.858369> [14 Nov 2020]

Doyle, J.P., Su, Y., and Kunkel, T. (2020) 'Athlete Branding via Social Media: Examining the Factors Influencing Consumer Engagement on Instagram'. European Sport Management Quarterly [online] 1-21. available from <https://www.tandfonline.com/doi/full/10.1080/16184742.2020.1806897> [22 September 2020] 
Duffy, B.E. and Hund, E. (2015) "“Having It All” on Social Media: Entrepreneurial Femininity and Self-Branding among Fashion Bloggers'. Social Media+ Society 1 (2), 2056305115604337

Ellis, C., Adams, T.E., and Bochner, A.P. (2011) 'Autoethnography: An Overview'. Historical Social Research/Historische Sozialforschung 273-290

Evans, J.R. (2017) ‘A Strategic Approach to Self-Branding'. Journal of Global Scholars of Marketing Science 27 (4), 270-311

Evans, N.J., Phua, J., Lim, J., and Jun, H. (2017) 'Disclosing Instagram Influencer Advertising: The Effects of Disclosure Language on Advertising Recognition, Attitudes, and Behavioral Intent'. Journal of Interactive Advertising 17 (2), 138-149

Filo, K., Lock, D., and Karg, A. (2015) 'Sport and Social Media Research: A Review'. Sport Management Review 18 (2), 166-181

Gainor, K. (2017) Self-Presentation of Male and Female Athletes on Instagram: A Continuation of Gender Roles Found in Advertisements?

Garratt, D. (2015) 'Psychoanalytic-Autoethnography: Troubling Natural Bodybuilding'. Qualitative Inquiry 21 (4), 343-353

Get Certified! Nutrition \& Personal Training Certifications, NASM (n.d.) available from <https://www.nasm.org/> [26 September 2020]

Geurin, A.N. and McNary, E.L. (2020) 'Athletes as Ambush Marketers? An Examination of Rule 40 and Athletes' Social Media Use during the 2016 Rio Olympic Games'. European Sport Management Quarterly 1-18

Geurin-Eagleman, A.N. and Burch, L.M. (2016) 'Communicating via Photographs: A Gendered Analysis of Olympic Athletes' Visual Self-Presentation on Instagram'. Sport Management Review 19 (2), 133-145

Goffman, E. (1959) The Presentation of Self in Everyday Life. New York: Anchor. 1963 Stigma. Englewood Cliffs, NJ: Prentice-Hall

Hambrick, M.E. and Mahoney, T.Q. (2011) “'It's Incredible-Trust Me”: Exploring the Role of Celebrity Athletes as Marketers in Online Social Networks'. International Journal of Sport Management and Marketing 10 (34), 161-179

Hambrick, M.E., Simmons, J.M., Greenhalgh, G.P., and Greenwell, T.C. (2010) 'Understanding Professional Athletes' Use of Twitter: A Content Analysis of Athlete Tweets'. International Journal of Sport Communication 3 (4), 454-471

Hasaan, A., Kerem, K., Biscaia, R., and Agyemang, K.J.A. (2018) 'A Conceptual Framework to Understand the Creation of Athlete Brand and Its Implications'. International Journal of Sport Management and Marketing [online] 18 (3), 169. available from <http://www.inderscience.com/link.php?id=91753> [22 Septe. 2020]

Hayano, D.M. (1979) ‘Auto-Ethnography: Paradigms, Problems, and Prospects'. Human Organization 38 (1), 99 104

Hodge, C. and Walker, M. (2015) 'Personal Branding: A Perspective from the Professional Athlete-Level-ofAnalysis'. International Journal of Sport Management and Marketing 16 (1-2), 112-131

Hubbard, B. (2017) Saudi Arabia Agrees to Let Women Drive - The New York Times [online] available from <https://www.nytimes.com/2017/09/26/world/middleeast/saudi-arabia-women-drive.html> [9 January 2021]

Irish, T., Cavallerio, F., and McDonald, K. (2018) “'Sport Saved My Life” but "I Am Tired of Being an Alien!”: Stories from the Life of a Deaf Athlete'. Psychology of Sport and Exercise 37, 179-187

Jensen Schau, H. and Gilly, M.C. (2003) 'We Are What We Post? Self-Presentation in Personal Web Space'. Journal of Consumer Research 30 (3), 385-404

Kantsepolsky, B. (2019) Exploration of Barriers to and Enablers for Entrepreneurship at Subsidiaries of Multinational Corporations: Analytic Autoethnography.

Knijnik, J. (2015) 'Feeling at Home: An Autoethnographic Account of an Immigrant Football Fan in Western Sydney'. Leisure Studies [online] 34 (1), 34-41. available from <http://www.tandfonline.com/doi/abs/10.1080/02614367.2014.939991> [14 November 2020]

Kunkel, T., Doyle, J., and Na, S. (2020) 'Becoming More than an Athlete: Developing an Athlete's Personal Brand Using Strategic Philanthropy’. European Sport Management Quarterly 1-21 
Lapadat, J.C. (2017) 'Ethics in Autoethnography and Collaborative Autoethnography'. Qualitative Inquiry [online] 23 (8), 589-603. available from <http://journals.sagepub.com/doi/10.1177/1077800417704462> [24 November 2020]

Lebel, K. and Danylchuk, K. (2014a) 'Facing off on Twitter: A Generation Y Interpretation of Professional Athlete Profile Pictures'. International Journal of Sport Communication 7 (3), 317-336

Lebel, K. and Danylchuk, K. (2014b) 'An Audience Interpretation of Professional Athlete Self-Presentation on Twitter.' Journal of Applied Sport Management 6 (2)

Lebel, K. and Danylchuk, K. (2012) ‘How Tweet It Is: A Gendered Analysis of Professional Tennis Players' SelfPresentation on Twitter'. International Journal of Sport Communication [online] 5 (4), 461-480. available from <https://journals.humankinetics.com/view/journals/ijsc/5/4/article-p461.xml> [22 Sept. 2020]

Liu, R. and Suh, A. (2017) 'Self-Branding on Social Media: An Analysis of Style Bloggers on Instagram'. Procedia Computer Science [online] 124, 12-20. available from <http://www.sciencedirect.com/science/article/pii/S1877050917328922> [15 September 2020]

London 2012 Olympics (2012) 'London 2012 Olympics: Saudi Arabian Women to Compete'. BBC News [online] 12 July. available from <https://www.bbc.com/news/world-middle-east-18813543> [16 September 2020]

Marwick, A.E. and Boyd, D. (2011) 'I Tweet Honestly, I Tweet Passionately: Twitter Users, Context Collapse, and the Imagined Audience'. New Media \& Society 13 (1), 114-133

McMahon, J. and McGannon, K. (2017) 'Re-Immersing into Elite Swimming Culture: A Meta-Autoethnography by a Former Elite Swimmer'. Sociology of Sport Journal 34 (3), 223-234

Mejova, Y. and Benkhedda, Y. (2017) ‘\# Halal Culture on Instagram'. Frontiers in Digital Humanities 4, 21

Miller, H. (1995) 'The Presentation of Self in Electronic Life: Goffman on the Internet'. in Embodied Knowledge and Virtual Space Conference. held 1995

Montoya, P. and Vandehey, T. (2009) The Brand Called You. McGraw-Hill

Mouria, H. (2018) An Examination of Cultural Sharing by Saudi Citizens Using Instagram. Arkansas State University

Na, S., Kunkel, T., and Doyle, J. (2020) 'Exploring Athlete Brand Image Development on Social Media: The Role of Signalling through Source Credibility'. European Sport Management Quarterly 20 (1), 88-108

Otayf, K.N. (2017) Identifying and Comparing the Influence of Instagram on the Creativity and Design Process of Female Fashion Design Students in Saudi Arabia and in the United States.

Park, J., Williams, A., and Son, S. (2020) 'Social Media as a Personal Branding Tool: A Qualitative Study of Student-Athletes' Perceptions and Behaviors'. Journal of Athlete Development and Experience [online] 2 (1). available from <https://scholarworks.bgsu.edu/jade/vol2/iss1/4/> [15 September 2020]

Parmentier, M.-A. and Fischer, E. (2012) 'How Athletes Build Their Brands'. International Journal of Sport Management and Marketing 11 (1-2), 106-124

Parry, K.D. (2012) 'Game of Two Passions: A Football Fan's Autoethnography'. Qualitative Research Journal [online] $\quad 12 \quad(2), \quad 238-250 . \quad$ available <https://www.emerald.com/insight/content/doi/10.1108/14439881211248374/full/html> [14 Nov. 2020]

Pegoraro, A. (2010) 'Look Who's Talking-Athletes on Twitter: A Case Study'. International Journal of Sport Communication 3 (4), 501-514

Pilgrim, K. and Bohnet-Joschko, S. (2019) 'Selling Health and Happiness How Influencers Communicate on Instagram about Dieting and Exercise: Mixed Methods Research'. BMC Public Health 19 (1), 1054

Pink, S. (2016) 'Digital Ethnography'. Innovative Methods in Media and Communication Research 161-165

Pink, S. (2013) Doing Visual Ethnography. Sage

PNU, sports authority (2016) PNU, Sports Authority Sign Deal to Promote Women's Sport in Saudi Arabia [online] available from <https://www.arabnews.com/node/1015386/saudi-arabia> [16 September 2020]

Samargandi, T.H. (2018) The Attitudes of Saudi Teachers toward Teaching Physical Education for Girls at Public Schools in Jeddah [online] Ph.D. Ann Arbor: University of Arkansas. available from <https://search.proquest.com/docview/2032539955?accountid=43793> 
Sanderson, J. (2013) 'Just Warming up: Logan Morrison, Twitter, Athlete Identity, and Building the Brand'. in Sports and Identity. Routledge, 224-238

Saudi Arabia considers allowing (2012) ‘Saudi Arabia Considers Allowing Women Sport Clubs'. [28 April 2012] available from <https://en.amwalalghad.com/saudi-arabia-considers-allowing-women-sport-clubs/> [16 September 2020]

Saudi public schools (2017) 'Saudi Public Schools to Introduce Physical Education for Girls | Al Arabiya English'. AlArabiya.Net [online] 11 July. available from <https://english.alarabiya.net/en/variety/2017/07/11/Saudipublic-schools-to-introduce-physical-education-for-girls> [16 September 2020]

Schaeperkoetter, C.C. (2017) 'Basketball Officiating as a Gendered Arena: An Autoethnography'. Sport Management Review [online] 20 (1), 128-141. available from <https://linkinghub.elsevier.com/retrieve/pii/S1441352316300298> [14 November 2020]

Sharifzadeh, Z., Brison, N., and Bennett, G. (2019) 'Personal Branding on Instagram: An Examination of Iranian Professional Athletes'. Sport Marketing Association Conference

Shreffler, M.B., Hancock, M.G., and Schmidt, S.H. (2016) 'Self-Presentation of Female Athletes: A Content Analysis of Athlete Avatars'. International Journal of Sport Communication 9 (4), 460-475

Smith, B. and Sparkes, A.C. (2020) 'Qualitative Research'. Handbook of Sport Psychology 999-1019

Smith, L.R. and Sanderson, J. (2015) 'I'm Going to Instagram It! An Analysis of Athlete Self-Presentation on Instagram'. Journal of Broadcasting \& Electronic Media 59 (2), 342-358

Su, Y., Baker, B.J., Doyle, J.P., and Kunkel, T. (2020) 'The Rise of an Athlete Brand: Factors Influencing the Social Media Following of Athletes.' Sport Marketing Quarterly 29 (1)

Tahran, F. (2013) Saudi girls banned from sporting activities [online] available from <https://www.arabstoday.net/en/207/saudi-girls-banned-from-sport-activities-at-school> [16 Sept. 2020]

Toffoletti, K. and Thorpe, H. (2018) 'The Athletic Labour of Femininity: The Branding an...: Full Text Finder Results'. Journal of Consumer Culture [online] 18 (2). available from <http://0o10nucbw.y.http.resolver.ebscohost.com.kau.proxy.deepknowledge.io/openurl?sid=EBSCO\%3aas n\&genre $=$ article $\&$ issn $=14695405 \&$ ISBN $=\&$ volume $=18 \&$ issue $=2 \&$ date $=20180501 \&$ spage $=298 \&$ pages $=29$ 8 -

316\&title $=$ Journal + of + Consumer + Culture $\&$ atitle $=$ The + athletic + labour + of + femininity $\% 3 a+$ The + branding + and+consumption+of+global+celebrity+sportswomen+on+Instagram.\&aulast=Toffoletti $\% 2 \mathrm{c}+\mathrm{Kim} \& \mathrm{id}=\mathrm{DO}$ I\%3a10.1177\%2f1469540517747068\&site=ftf-live> [15 September 2020]

Toumi, H. (2013) 'Saudi Arabia Opens First Sports Centre for Women | Saudi - Gulf News'. Gulf News [online] 3 June. available from <https://gulfnews.com/world/gulf/saudi/saudi-arabia-opens-first-sports-centre-forwomen-1.1192220>

Van Itallie, A., Corry, K., Vandelanotte, C., and Duncan, M. (2018) 'Effectiveness of a Social Media Marketing Campaign to Increase Awareness and Membership of a Physical Activity Website'. Journal of Science and Medicine in Sport 21, S87

Wojcicki, T. (2013) A Social Cognitive Approach to Influencing Adolescent Physical Activity Behavior via Social Media. University of Illinois at Urbana-Champaign

Zavattaro, S. (2014) 'Athletic Identity-or an Autoethnography of Almost Losing a Leg'. Qualitative Research Journal

- Qantara.de (n.d.) available from <https://ar.qantara.de/content/ljdl-hwl-hqwq-lmrfy-lslm-hqwq-lmr-lmslm-bywn-lgrbmbryly-mqn-wswr-nmty-0> [11 October 2020]

\section{Copyrights}

Copyright for this article is retained by the author(s), with first publication rights granted to the journal.

This is an open-access article distributed under the terms and conditions of the Creative Commons Attribution license (http://creativecommons.org/licenses/by/4.0/). 